\title{
AN ALGORITHM FOR THE DESIGN OF AN AXIAL FLOW COMPRESSOR OF A POWER GENERATION GAS TURBINE
}

\author{
A. I. Obanor 1 , 0. J. Unuareokpa² and H. 0. Egware ${ }^{3}$

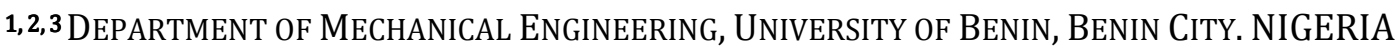 \\ E-mail addresses:1 aiobanor@yahoo.com, ${ }^{2}$ omoskop@yahoo.com, ${ }^{3}$ henryegware@yahoo.com
}

\begin{abstract}
This paper focuses on the development of an algorithm for designing an axial flow compressor for a power generation gas turbine and attempts to bring to the public domain some parameters regarded as propriety data by plant manufacturers. The theory used in this work is based on simple thermodynamics and aerodynamics principles in a mean stream line analysis that assumes that the flow conditions prevailing at the mean radius fully represent the flow at all other radii. Gas Turbine Unit II (GT-II) in Omotosho Power Plant Phase I located in Ondo state was used to validate this work. The specifications used include mass flow rate, rotational speed, number of stages, pressure ratio, ambient air temperature and pressure etc. A computer program was written based on the formulated algorithm and the code was implemented in Microsoft Excel. The axial velocity was obtained using an iterative process that converged to a value of $163.74 \mathrm{~m} / \mathrm{s}$ for the design condition. The blade camber angles for each stage of the compressor were also determined using iterative processes. The results showed a compressor overall stagnation temperature rise of $354.5^{\circ} \mathrm{C}$ and work input of $51.5 \mathrm{MW}$ at an ambient air temperature of $15^{\circ} \mathrm{C}$. The stagnation temperature rise and compressor work input were computed to be $369^{\circ} \mathrm{C}$ and $53.6 \mathrm{MW}$ respectively at an ambient air temperature of $27^{\circ} \mathrm{C}$ and which agrees reasonably well with the measured values of $375^{\circ} \mathrm{C}$ and 54.6MW in GT-II. The total to total efficiency was 0.86 for both ambient air temperature values.
\end{abstract}

Keywords: Algorithm, Ambient air temperature, Axial flow compressor, Gas turbine, Power generation

\section{INTRODUCTION}

The increasing demand for electricity in Nigeria has led to the building of several power stations all over the nation, especially gas driven power plants. The gas turbine power plants in Nigeria are sited in locations where the standard ambient air temperature condition of $15^{\circ} \mathrm{C}$ specified by the International Organization for Standardization (ISO) for rating them rarely occurs. The ambient air temperatures occurring in these locations which predominantly exceed $15^{\circ} \mathrm{C}$ cause a lower thermal performance of the power plants. The gas turbine or combustion turbine power plants were primarily preferred to other thermal plants because of their low capital cost, short installation period and abundant availability of natural gas [1]. Among the gas power plants is the Omotosho power plant, located in Ondo state. It has eight similar gas turbine units (GT-I to GT-VIII) with individual installed capacity of 42.1MW.
The various components of this plant, like all other power plants in Nigeria, are designed and manufactured by companies outside the country; foreign companies also largely undertake their assembling, installation and commissioning. The design parameters for the various components termed "proprietary information" or data are often not disclosed, making it difficult for the Nigerian engineer to carry out proper maintenance work on the plant. This invariably means that the Nigerian engineers are left in the dark as regards the true performance of the power stations in their care. This lack of knowledge of the design parameters of the major components of this plant and a poor maintenance culture have resulted in many units breaking down and hence requiring the attention of manufacturers.

When designing a new compressor, a good start is to create a preliminary design for the compressor. A good model can be generated by just a handful of design specifications. 


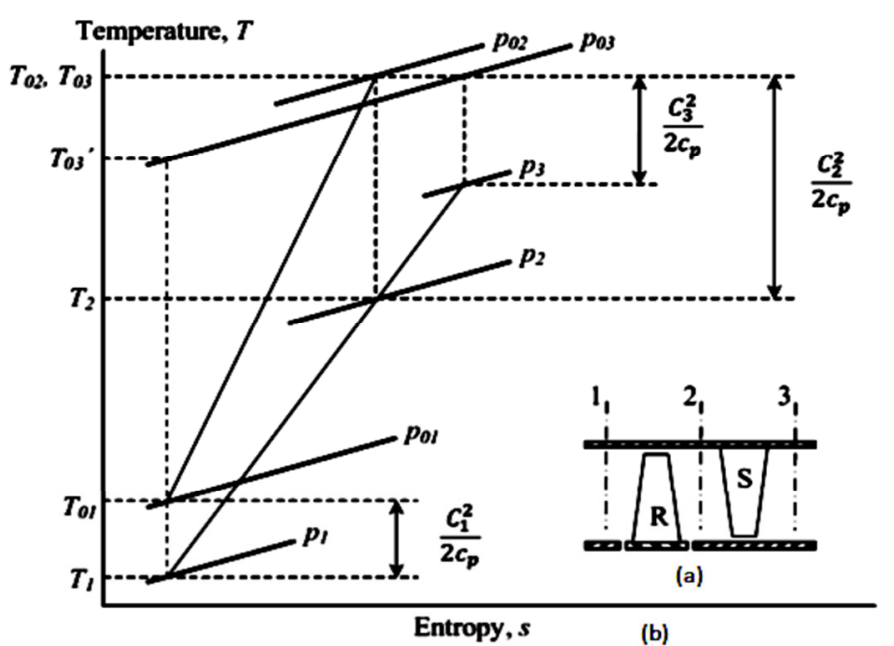

Figure 1: Compressor stage and T-s diagram

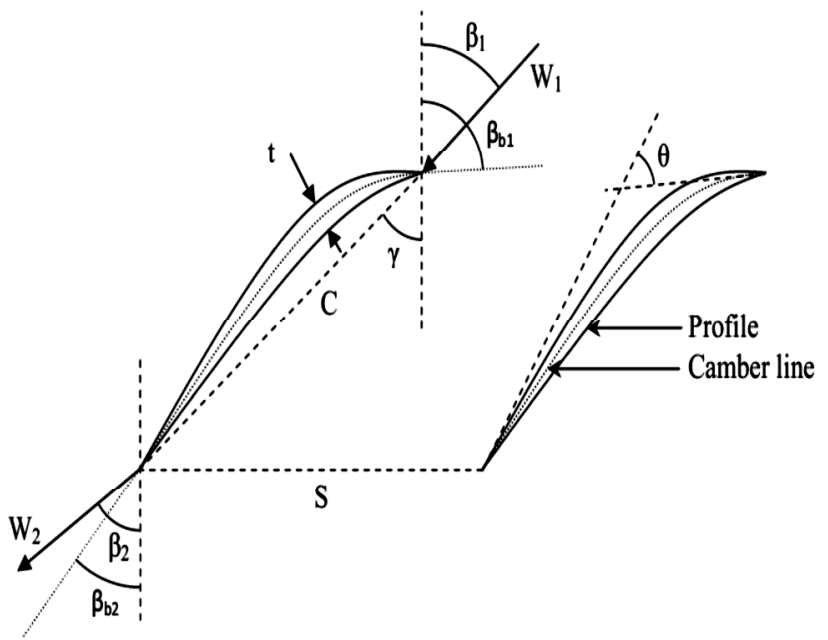

Figure 2: Compressor cascade geometry
The modeling techniques used are based on thermodynamic and aerodynamic correlations. This base design will make up for about $60-70 \%$ of the finished design [2]. In this first stage of designing a new compressor, designs that would not work or have poor efficiency can be improved, therefore, creating a base design for an existing compressor, such as in GTII. This will help the Nigerian engineer understand the compressor better, with a view to manufacturing a compressor or even the entire gas turbine in the country as enunciated in [3].

The performance of a gas turbine plant is a function of how well the three major components (compressor, combustion chamber and turbine) are designed. Creating a good and simple compressor base design will go a long way in improving the performance and efficiency of the gas turbine. This work is aimed at providing a simple but reliable method of carrying out a preliminary design of an axial flow compressor. The objective is to open up the otherwise shut doors to the design parameters of an axial flow compressor and to encourage the Nigerian engineer, especially those in the field of thermal power, to attempt the detailed design and modeling of an axial flow compressor. Dixon [4] and Saravanamutto et al. [5] have thoroughly treated the fundamentals and theory of axial flow compressors which are considered in this paper.

Many researchers have conducted various works on the design of axial flow compressors [6-12]. These are foreign research works that are suitable for the weather conditions in locations where the studies were carried out. A country such as Nigeria that is currently committing huge investments on building gas turbine power plants should motivate her

Nigerian Journal of Technology, engineers to embark on research work entailing the design, manufacture, installation, optimal operation and maintenance of these plants[1].

\section{METHODOLOGY}

\subsection{Data Gathering}

In designing a new compressor, a number of parameters must be chosen to specify the geometry and operating conditions for the compressor. Likewise in creating a base design, these parameters must be gathered. Data used for this work were collected by the authors from plant operating manuals, drawings and from a General Electric performance engineer (B. Kazeem, personal communication, June 2012). Some data were also taken from those engraved on the compressor.

\subsection{Compressor Stage}

A compressor stage is defined as a rotor row followed by a stator row. Multistage axial compressors may have as many as twenty stages [13] in some applications, making the machine rather lengthy. The rotor blades are fixed to the rotor drum and the stator blades to the casing. The inlet guide vanes are not regarded as part of the first compressor stage and are treated separately $[4,5]$. All the power is absorbed in the rotor and the stator transforms the kinetic energy which has been absorbed by the rotor into an increase in static pressure. The stagnation temperature remains constant throughout the stator, since there is no work fed into the fluid. Figure 1a shows a sketch of a typical compressor stage with $\mathrm{R}$ indicating the rotor row and $S$ the stator row. Figure $1 \mathrm{~b}$ is the T-s diagram for the stage. Figure 2 illustrates the cascade geometry. 


\subsection{Calculation Procedure}

The calculation procedure for the preliminary design of axial flow compressor consists of five major steps as follows:

i) Inlet geometry calculations

ii) Compressor exit geometry and temperature rise calculations

iii) Stage by stage design calculations

iv) Calculations of air angles from root to tip

v) Blade design calculations.

Tables 1 and 2 show the input parameters used to carry out the preliminary design calculations for the axial flow compressor. Figure 3 is a flow chart illustrating the calculation procedure

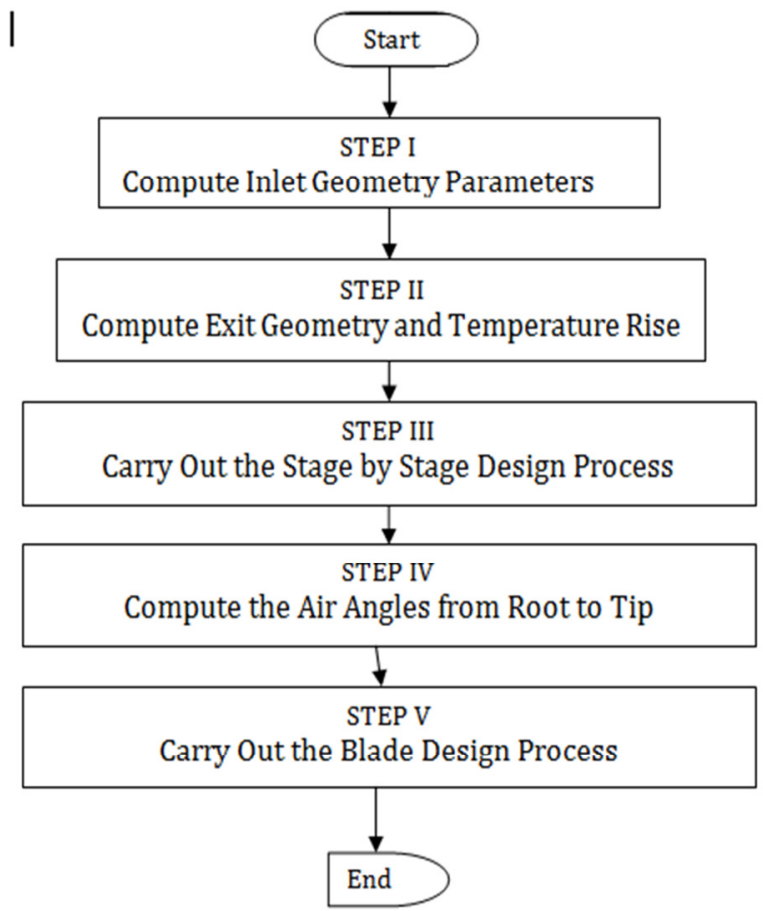

Figure 3: Calculation Procedure

Table 1: Main specification input parameters

\begin{tabular}{ll}
\hline Main Specification & \\
\hline Type of compressor design & $\mathrm{CMD}$ \\
Mass flow & $144.57 \mathrm{~kg} / \mathrm{s}$ \\
Number of stages & 17 \\
Pressure ratio & 12.2 \\
Rotational speed & $5163 \mathrm{rpm}$ \\
Degree of reaction at mean & \\
radius & 0.55 \\
Inlet flow angle & $15^{\circ}$ \\
Stage flow coefficient & 0.65 \\
Root tip ratio & 0.5 \\
Ambient air temperature & $15^{\circ} \mathrm{C}$ \\
Ambient pressure & $1.01325 \mathrm{bar}$ \\
Polytropic efficiency & 0.90 \\
\hline
\end{tabular}

Table 2: Detailed specification input parameters

\begin{tabular}{lllll}
\hline \multirow{2}{*}{ Detailed Specification } & \multicolumn{2}{l}{ First Stage } & \multicolumn{2}{l}{ Last Stage } \\
\cline { 2 - 5 } & Rotor & Stator & Rotor & Stator \\
\hline Aspect Ratio, $A R$ & 2.4 & 3.7 & 1 & 1 \\
Thickness Chord Ratio, & & & & \\
$t / c$ & 0.06 & 0.06 & 0.06 & 0.06 \\
Work Done Factor, $\lambda$ & 0.98 & 0.98 & 0.83 & 0.83 \\
Tip Clearance, $\varepsilon / c$ & 0.02 & 0 & 0.02 & 0 \\
\hline
\end{tabular}

\subsubsection{Step I: Inlet Geometry}

To be able to determine the inlet geometry, the inlet flow velocity, $C_{a}$, must be known. Since this velocity is unknown, an iterative process must be used. By assuming the value of $C_{a}$, and using (1) to (9), a new inlet flow velocity can be calculated. This value is then compared with assumed value and the calculation is repeated until convergence is obtained. The calculation procedure is illustrated in Figure 4.

$$
\begin{aligned}
& C=\frac{C_{a}}{\cos \alpha} \\
& T=T_{0}-\frac{C^{2}}{2 c_{p}} \\
& p=p_{o}\left(\frac{T}{T_{0}}\right)^{\frac{\gamma}{\gamma-1}} \\
& \rho=\frac{\mathrm{p}}{\mathrm{R} \mathrm{T}}
\end{aligned}
$$

$r_{t}=\left[\frac{\dot{m}}{\pi \rho C_{a}\left(1-\frac{r_{r}}{r_{t}}\right)^{2}}\right]^{\frac{1}{2}}$

$$
r_{r}=r_{t} \cdot \frac{r_{r}}{r_{t}}
$$

$r_{r m s}=\left(\frac{r_{t}^{2}+r_{r}^{2}}{2}\right)^{\frac{1}{2}}$

$U_{r m s}=\frac{2 \pi r_{r m s} R P M}{60}$

$$
C_{a, \text { new }}=U_{\text {rms }} \phi
$$

\subsubsection{Step II: Compressor Exit Geometry and Stage Temperature Rise}

With respect to Figure 1a, Figure 5 shows the velocity diagrams for flow entering and leaving the rotor. With the inlet geometry estimated, it is instructive now to estimate the annulus dimensions at exit from the compressor, and for these preliminary calculations it will be assumed that the mean radius is kept constant for all stages. 


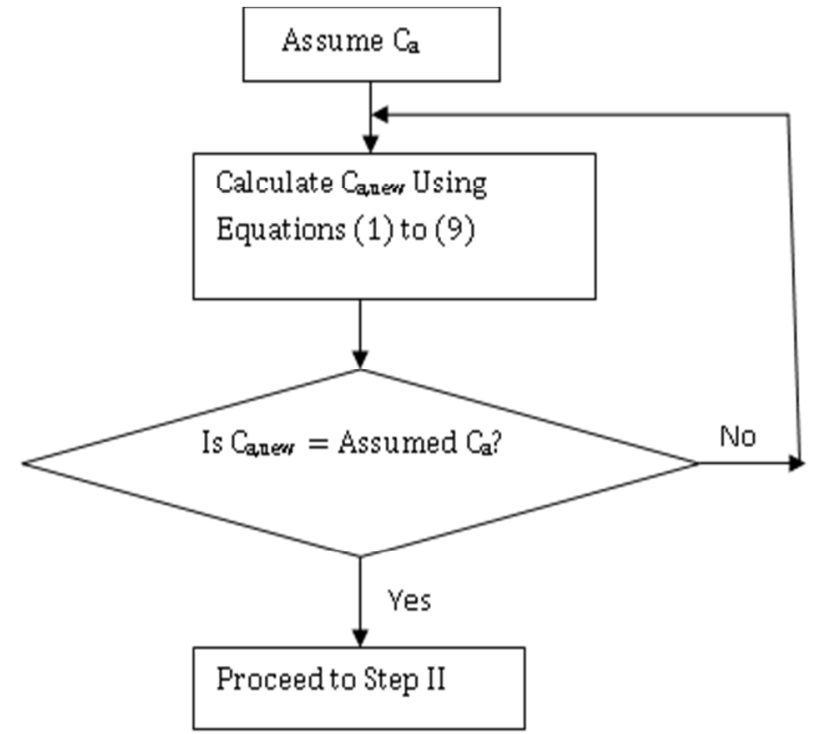

Figure 4: Step I calculation procedure
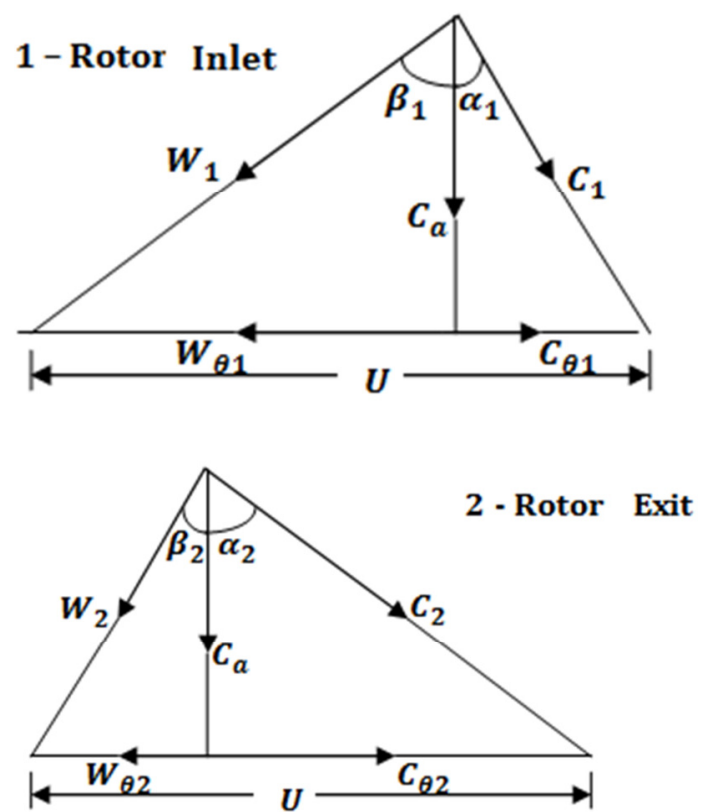

Figure 5: Velocity diagrams for flow at rotor inlet and exit

The compressor delivery pressure,

$$
\mathrm{p}_{0 \mathrm{exit}}=\mathrm{p}_{01 \mathrm{X}} \mathrm{r}_{\mathrm{p}}
$$

To estimate the compressor exit temperature, a polytropic efficiency of 0.9 is assumed for the compressor [5]. Thus:

$$
\begin{aligned}
T_{0 \text { exit }} & =T_{01}\left(\frac{p_{02}}{p_{01}}\right)^{\frac{n-1}{n}} \\
\frac{n-1}{n} & =\frac{1}{\eta_{\text {poly }}} \frac{\gamma-1}{\gamma}
\end{aligned}
$$

The static temperature $\left(T_{\text {exit }}\right)$, pressure $\left(p_{\text {exit }}\right)$ and density $\left(\rho_{\text {exit }}\right)$ at exit can readily be calculated using (2), (3) and (4) respectively.

The exit annulus area $\left(A_{\text {exit }}\right)$ is given by (13);

$$
A_{\text {exit }}=\frac{\dot{m}}{\rho_{\text {exit }} C_{a}}
$$

The mean radius $\left(\mathrm{r}_{\mathrm{m}}\right)$ is given by (14)

$$
r_{m}=\frac{r_{t}+r_{r}}{2}
$$

The blade height at exit, $\left(H_{\text {exit }}\right)$ is computed using (15)

$H_{\text {exit }}=\frac{A_{\text {exit }}}{2 \pi r_{m}}$

The radii at exit from the last section are calculated using (16) and (17).

$$
\begin{gathered}
r_{t}=r_{m}+\frac{H_{\text {exit }}}{2} \\
r_{r}=r_{m}-\frac{H_{\text {exit }}}{2}
\end{gathered}
$$

The overall stagnation temperature rise through the compressor is calculated using (18).

$\Delta T_{0}=T_{0 e x i t}-T_{01}$

The average stage temperature rise $\Delta T_{0 s}$ is calculated using (19).

$\Delta T_{0 S}=\frac{\Delta T_{0}}{N}$

In (19), $N$ is the number of stages

The parameters calculated using (10) to (19) are presented in Table 3.

\section{Table 3: Some computer parameters from step II}

\begin{tabular}{llll}
\hline Temperature (K) & \multicolumn{3}{c}{ Height/radius (m) } \\
\hline $\mathrm{T}_{\text {oexit }}$ & 637.5 & $\mathrm{H}_{\text {oexit }}$ & 0.0496 \\
$\mathrm{~T}_{\text {exit }}$ & 624.2 & $\mathrm{r}_{\mathrm{t}}$ & 0.4668 \\
$\Delta \mathrm{To}$ & 349.4 & $\mathrm{r}_{\mathrm{r}}$ & 0.4172 \\
$\Delta \mathrm{Tos}$ & 20.55 & & \\
Exit parameters & & & \\
$\mathrm{p}_{\text {oexit }}($ bar $)$ & 12.362 & \\
$\mathrm{p}_{\text {exit }}(\mathrm{bar})$ & 11.480 & \\
$\mathrm{~A}_{\text {exit }}\left(\mathrm{m}^{2}\right)$ & 0.1378 & \\
$\rho_{\text {exit }}\left(\mathrm{kg} / \mathrm{m}^{3}\right)$ & 6.408 & \\
\hline
\end{tabular}

\subsubsection{Step III: Stage By Stage Design}

The evaluation of blade speed, $\mathrm{U}$, at the mean radius is calculated using (20). This is constant throughout the entire compressor stages

$U=\frac{2 \pi r_{m} R P M}{60}$

Equation (21) which is stated in [5] is used to calculate the change in swirl velocity $\Delta C_{\text {回. }}$.

$\Delta C_{\theta}=\frac{c_{p} \Delta T_{0 S}}{\lambda U}$

Equations (22) to (28) can be obtained by analyzing Figure 5 trigonometrically.

$$
\begin{aligned}
& C_{\theta 1}=C_{a} \tan \alpha_{1} \\
& C_{\theta 2}=\Delta C_{\theta}+C_{\theta 1}
\end{aligned}
$$


$\beta_{1}=\tan ^{-1}\left(\frac{U-C_{\theta 1}}{C_{a}}\right)$

$\beta_{2}=\tan ^{-1}\left(\frac{U-C_{\theta 2}}{C_{a}}\right)$

$\alpha_{2}=\tan ^{-1}\left(\frac{C_{\theta 2}}{C_{a}}\right)$

$W_{1}=\frac{C_{a}}{\cos \beta_{1}}$

$W_{2}=\frac{C_{a}}{\cos \beta_{2}}$

The de Haller number for the rotor $\left(d H_{\text {rotor }}\right)$ is given by (29)

$d H_{\text {rotor }}=\frac{W_{2}}{W_{1}}$

The relationship between the stagnation pressure $\mathrm{p}_{\mathrm{o}}$ and stagnation temperature $\mathrm{T}_{\mathrm{o}}$ across the rotor is given by (30)

$p_{02}=p_{01}\left(\frac{T_{02}}{T_{01}}\right)^{\frac{\gamma}{\gamma-1}}$

Equation (31) which is stated in [5] can be used to calculate the stagnation pressure of air at end of the first stage of compression $\mathrm{p}_{03}$.

$p_{03}=\left(p_{01}+\frac{\eta_{s} \Delta T_{0 s}}{T_{01}}\right)^{\frac{\gamma}{\gamma-1}}$

where, $\eta_{s}$ is the stage isentropic efficiency.

The temperature of the air at the end of the first stage of compression $T_{03}$ is given by (32).

$T_{03}=T_{01}+\Delta T_{\text {os }}$

The local sonic velocity, a, is given by (33).

$a=\sqrt{\gamma R T}$

The local Mach number for the flow, $M$ is given by

(34).

$M=\frac{W}{a}$

The relationship between the pressure rise coefficient $\kappa$ and de Haller number,

$\mathrm{dH}$, which is derived in [3] is given by (35).

$\kappa=1-(d H)^{2}$

The relationship between the pitch chord ratio , s/c, to $\kappa$ which stated in [14] is given by (36).

$\frac{s}{c}=9(0.567-\kappa)$

The diffusion factor DF, which is stated in [2] is given by (37).
$D F=1-\frac{W_{2}}{W_{1}}+\frac{\left|\Delta W_{\theta}\right|}{2 \sigma W_{1}}$

$\Delta W_{\theta}=W_{\theta 2}-W_{\theta 1}$

where $W_{\theta 1}$ and $W_{\theta 2}$ are the tangential components of $\mathrm{W}_{1}$ and $\mathrm{W}_{2}$ as indicated in Figure 5.

The relationship between the stagnation enthalpy $h_{01}$, $\mathrm{h}_{02}$ and $\mathrm{h}_{03}$ and stagnation temperature $\mathrm{T}_{02}$ and $\mathrm{T}_{01}$ is given by (39).

$h_{03}=h_{02}=h_{01}+c_{p}\left(T_{02}-T_{01}\right)$

The relationship between static and stagnation parameters of the flow are as follows:

For enthalpy,

$$
h=h_{0}-\frac{C^{2}}{2}
$$

For pressure,

$$
p=p_{0}\left(\frac{T}{T_{0}}\right)^{\frac{\gamma}{\gamma-1}}
$$

The parameters computed using (20) to (41) are presented in Table 4.

\subsubsection{Step IV Computation of Air Angles from Root to Tip}

The air angles are computed using a free vortex design method [5]. Considering the first stage the blade speeds at the tip and root, $\mathrm{U}_{1 \mathrm{t}}$ and $\mathrm{U}_{1 \mathrm{r}}$ are computed using (20).

For a free vortex design, $C_{\theta} r=$ constant is stated in [5].

Thus

$\mathrm{C}_{\theta 1 \mathrm{t}}=\mathrm{C}_{\theta 1} \cdot \frac{r_{m}}{r_{1 t}}$ and $\mathrm{C}_{\theta 1 r}=\mathrm{C}_{\theta 1} \cdot \frac{r_{m}}{r_{1 r}}$

The angles $\beta_{1 \mathrm{t}}$ and $\beta_{1 \mathrm{r}}$ can be computed using (24).

The stagnation temperature and pressure at exit from the first stage, which were computed to be $306.15 \mathrm{~K}$ and 1.189bar respectively, can be seen in Table 4 .

The stator exit parameters $C_{3}, T_{3}, p_{3}, \rho_{3}, A_{3}, H_{3}, r_{3 t}$ and $r_{3 r}$ which can be seen in Table 5 where computed using (1) ,(2),(3),(4), (13), (15),(16) and (17) respectively.

With negligible error it can be assumed that the radii at exit from rotor blades are the mean of those at rotor inlet and stator exit [5].

$r_{2 t}=\left(\frac{r_{1 t}+r_{3 t}}{2}\right)$

$r_{2 r}=\left(\frac{r_{1 r}+r_{3 r}}{2}\right)$ 
Table 4: Some computed parameters from step III

\begin{tabular}{cccccc}
\hline \multicolumn{2}{c}{ Velocity $(\mathrm{m} / \mathrm{s})$} & \multicolumn{2}{c}{ Ratio } & \multicolumn{2}{c}{ Enthalpy $(\mathrm{kJ} / \mathrm{kg})$} \\
\hline $\mathrm{U}$ & 238.98 & $\mathrm{dH}_{\text {rotor }}$ & 0.792 & $\mathrm{~h}_{01}$ & 289.59 \\
$\mathrm{C}_{\ominus}$ & 77.24 & $\mathrm{M}_{1}$ & 0.7678 & $\mathrm{~h}_{02}$ & 307.68 \\
$\mathrm{C}_{\ominus 1}$ & 43.87 & $\mathrm{M}_{2}$ & 0.5957 & $\mathrm{~h}_{1}$ & 275.22 \\
$\mathrm{C}_{\theta 2}$ & 121.11 & $\mathrm{~K}$ & 0.3726 & $\mathrm{~h}_{2}$ & 286.94 \\
$\mathrm{~W}_{1}$ & 254.72 & $\mathrm{~s} / \mathrm{c}$ & 1.7495 & $\mathrm{~h}_{3}$ & 292.34 \\
$\mathrm{~W}_{2}$ & 201.75 & $\mathrm{DF}$ & 0.4732 & & \\
$\mathrm{a}_{1}$ & 331.71 & & & & \\
$\mathrm{a}_{2}$ & 338 & & & & \\
Other parameters & & & & \\
$\mathrm{p}_{03}($ bar $)$ & 1.1894 & & & & \\
$\mathrm{p}_{02}($ bar $)$ & 1.2263 & & & & \\
$\mathrm{p}_{2}($ bar $)$ & 0.9811 & & & & \\
$\beta_{1}\left({ }^{0}\right)$ & 49.5 & & & & \\
$\beta_{2}\left(^{0}\right)$ & 35.75 & & & & \\
$\alpha_{1}\left({ }^{0}\right)$ & 36.49 & & & & \\
$\mathrm{~T}_{03}(\mathrm{~K})$ & 306.15 & & & & \\
\hline
\end{tabular}

Table 5: Computed parameter from step IV Height or Radius (m) Velocity (m/s)

$\begin{array}{llll}\mathrm{r}_{1 \mathrm{t}} & 0.5874 & \mathrm{U}_{1 \mathrm{t}} & 318.64 \\ \mathrm{r}_{1 \mathrm{r}} & 0.2947 & \mathrm{U}_{1 \mathrm{r}} & 159.32 \\ \mathrm{r}_{2 \mathrm{t}} & 0.5824 & \mathrm{C}_{\Theta 1 \mathrm{t}} & 32.91 \\ \mathrm{r}_{2 \mathrm{r}} & 0.3016 & \mathrm{C}_{\Theta 1 \mathrm{r}} & 65.81 \\ \mathrm{r}_{3 \mathrm{t}} & 0.5755 & \mathrm{C}_{3} & 175.11 \\ \mathrm{r}_{3 \mathrm{r}} & 0.3086 & & \\ \mathrm{H}_{3} & 0.2669 & & \end{array}$

Other parameters

$\begin{array}{cc}\beta_{1 \mathrm{t}}\left({ }^{0}\right) & 60.19 \\ \beta_{1 \mathrm{r}}\left(^{0}\right) & 29.73 \\ \mathrm{p}_{3}(\mathrm{bar}) & 0.9945 \\ \mathrm{~T}_{3}(\mathrm{~K}) & 290.89 \\ \rho_{3}\left(\mathrm{~kg} / \mathrm{m}^{3}\right) & 1.191\end{array}$

$\mathrm{A}_{3}\left(\mathrm{~m}^{2}\right) \quad 0.7412$

The parameters computed in Step IV are shown in Table 5.

The blade tip and root values of $U$ at exit from the rotor $\left(U_{2 t}\right.$ and $\left.U_{2 r}\right)$ are $314.885 \mathrm{~m} / \mathrm{s}$ and $163.079 \mathrm{~m} / \mathrm{s}$ while the corresponding values for the swirl velocities

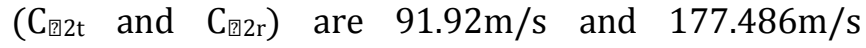
respectively.
The stator inlet, rotor exit and deflection angles calculated using (24), (25) and (26) are shown in Table 6.

Table 6: Stator inlet, rotor exit and deflection angles

\begin{tabular}{cc}
\hline Angles & Values \\
\hline$\alpha_{2 t}$ & $29.31^{0}$ \\
$\alpha_{2 r}$ & $47.31^{0}$ \\
$\beta_{2 t}$ & $53.71^{0}$ \\
$\beta_{2 r}$ & $-5.03^{0}$ \\
$\beta_{1 \mathrm{t}}-\beta_{2 \mathrm{t}}$ & $6.48^{0}$ \\
$\beta_{1}-\beta_{2}$ & $14.25^{0}$ \\
$\beta_{1 \mathrm{r}}-\beta_{2 \mathrm{r}}$ & $34.76^{0}$ \\
\hline
\end{tabular}

The degree of reaction $(\Lambda)$ as stated in [5] is given by (45).

$\Lambda=1-\frac{1}{R^{2}}\left(1-\Lambda_{m}\right)$.

where the radius ratio, $R=\frac{r_{2}}{r_{m}}$ and $\Lambda_{\mathrm{m}}$ is indicated in Table 1.

The degrees of reaction for blade tip and root calculated using (45) are 0.741 and 0.443 respectively.

The entire stage is now fully defined. This process is repeated for the remaining stages.

\subsubsection{Step V: Blade Design}

In designing the blade, an iteration procedure is needed to calculate the blade angles. An initial value is assumed for the blade camber angle $\Theta$. Using this value of $\theta$ and empirical correlations taken from [2, 15], the incidence angle $i$, deviation angle $\delta$ are computed. From the incidence and deviation angles, a new value of $\Theta$ is calculated and compared with the assumed value. This is then repeated until convergence is obtained.

The next thing is to determine the chord length which depends on the pitch, which itself is clearly dependent on the number of blades, $N$, in the row. When making a choice for this number, the aspect ratio of the blade has to be considered because of its effect on secondary losses.

The chord length is given by:

$$
c=\frac{H}{A R}
$$

Hence for values of blade height $\mathrm{H}$ and aspect ratio AR of $0.2947 \mathrm{~m}$ and 2.4 respectively,

$$
\begin{gathered}
c_{\text {rotor }}=\frac{0.2947}{2.4}=0.11279 \mathrm{~m} \\
S_{\text {rotor }}=\left(\frac{S}{c}\right)_{\text {rotor }} \times c_{\text {rotor }}=0.21482 \mathrm{~m}
\end{gathered}
$$




$$
N_{\text {rotor }}=\frac{2 \pi r_{m}}{S_{\text {rotor }}}=12.93
$$

It is desirable to avoid numbers with common multiples for the blades in successive rows to reduce the likelihood of introducing resonant forcing frequencies. One method of doing this is to choose an even number for the stator blades and prime numbers for the rotor blades. An appropriate number for the rotor blades in this stage would therefore be 13; calculation in the reverse order gives

$\mathrm{S}_{\text {rotor }}=0.214 \mathrm{~m}, \mathrm{c}_{\text {rotor }}=0.122 \mathrm{~m}$ and $\mathrm{AR}_{\text {rotor }}=2.413$. The same process is followed for the stator row to give $\mathrm{c}_{\text {stator }}=0.07625 \mathrm{~m}, \mathrm{~S}_{\text {stator }}=0.21015 \mathrm{~m}$ and $\mathrm{N}_{\text {stator }}=$ 13.21535
The corrections then become: $\mathrm{N}_{\text {stator }}=14, \mathrm{~S}_{\text {stator }}=$ $0.198 \mathrm{~m}, \mathrm{c}_{\text {stator }}=0.0720 \mathrm{~m}$ and $\mathrm{AR}_{\text {rotor }}=3.708$

\section{RESULTS AND DISCUSSION}

\subsection{Results}

The results of the preliminary design calculations are presented in Tables 7 to 11 and Figure 6. The static and stagnation properties of the air at various stages of the compressor, which were calculated using the computer program that was written based on the formulated algorithm are shown in Tables 7 and 8 respectively.

Table 7: Static properties

\begin{tabular}{rccccccccccc}
\hline Stage & $\begin{array}{c}\mathrm{T}_{1} \\
\mathrm{~K}\end{array}$ & $\begin{array}{c}\mathrm{T}_{2} \\
\mathrm{~K}\end{array}$ & $\begin{array}{c}\mathrm{T}_{3} \\
\mathrm{~K}\end{array}$ & $\begin{array}{c}\mathrm{p}_{1} \\
\mathrm{bar}\end{array}$ & $\begin{array}{c}\mathrm{p}_{2} \\
\mathrm{bar}\end{array}$ & $\begin{array}{c}\mathrm{p}_{3} \\
\mathrm{bar}\end{array}$ & $\begin{array}{c}\mathrm{h}_{1} \\
\mathrm{~kJ} / \mathrm{kg}\end{array}$ & $\begin{array}{c}\mathrm{h}_{2} \\
\mathrm{~kJ} / \mathrm{kg}\end{array}$ & $\begin{array}{c}\mathrm{h}_{3} \\
\mathrm{~kJ} / \mathrm{kg}\end{array}$ & $\begin{array}{c}\rho_{1} \\
\mathrm{~kg} / \mathrm{m}^{3}\end{array}$ & $\begin{array}{c}\rho_{3} \\
\mathrm{~kg} / \mathrm{m}^{3}\end{array}$ \\
\hline 1 & 273.85 & 285.51 & 290.89 & 0.84794 & 0.98117 & 0.99453 & 275.22 & 286.94 & 292.34 & 1.0789 & 1.1912 \\
2 & 290.89 & 302.16 & 311.92 & 0.99453 & 1.13602 & 1.24140 & 292.34 & 303.67 & 313.48 & 1.1912 & 1.3867 \\
3 & 311.92 & 323.09 & 332.94 & 1.24140 & 1.40418 & 1.52712 & 313.48 & 324.71 & 334.61 & 1.3867 & 1.5981 \\
4 & 332.94 & 344.03 & 353.97 & 1.52712 & 1.71258 & 1.85476 & 334.61 & 345.75 & 355.74 & 1.5981 & 1.8257 \\
5 & 353.97 & 364.96 & 375.00 & 1.85475 & 2.06424 & 2.22740 & 355.74 & 366.78 & 376.87 & 1.8257 & 2.0696 \\
6 & 375.00 & 385.89 & 396.03 & 2.22740 & 2.46219 & 2.64822 & 376.87 & 387.82 & 398.012 & 2.0696 & 2.3299 \\
7 & 396.03 & 406.81 & 417.05 & 2.64822 & 2.90931 & 3.12016 & 398.01 & 408.84 & 419.18 & 2.3299 & 2.6066 \\
8 & 417.05 & 427.75 & 438.08 & 3.12016 & 3.40929 & 3.64659 & 419.14 & 429.88 & 440.27 & 2.6066 & 2.9003 \\
9 & 438.08 & 448.67 & 459.11 & 3.64659 & 3.96463 & 4.23064 & 440.27 & 450.92 & 461.40 & 2.9003 & 3.2107 \\
10 & 459.11 & 469.60 & 480.14 & 4.23064 & 4.57867 & 4.87551 & 461.40 & 471.94 & 482.54 & 3.2107 & 3.5381 \\
11 & 480.14 & 490.52 & 501.17 & 4.87550 & 5.25457 & 5.58444 & 482.54 & 492.97 & 503.67 & 3.5381 & 3.8825 \\
12 & 501.17 & 511.44 & 522.20 & 5.58444 & 5.99548 & 6.36070 & 503.67 & 514.00 & 524.81 & 3.8825 & 4.2441 \\
13 & 522.20 & 532.36 & 543.23 & 6.36070 & 6.80461 & 7.20757 & 524.81 & 535.02 & 545.94 & 4.2441 & 4.6230 \\
14 & 543.23 & 553.27 & 564.26 & 7.20757 & 7.68515 & 8.12834 & 545.94 & 556.04 & 567.08 & 4.6230 & 5.0193 \\
15 & 564.26 & 574.19 & 585.29 & 8.12834 & 8.64034 & 9.12633 & 567.08 & 577.06 & 588.21 & 5.0193 & 5.4330 \\
16 & 585.29 & 595.10 & 621.14 & 9.12633 & 9.67339 & 11.10543 & 588.21 & 598.08 & 624.25 & 5.4330 & 6.2296 \\
17 & 606.4 & 616.22 & 642.60 & 10.20977 & 10.80052 & 12.36165 & 624.25 & 619.30 & 645.82 & 5.8664 & 6.7027 \\
\hline
\end{tabular}

Table 8: Stagnation properties

\begin{tabular}{|c|c|c|c|c|c|c|}
\hline Stage & $\mathrm{p}_{03} / \mathrm{p}_{\mathrm{o} 1}$ & $\begin{array}{l}\mathrm{p}_{\mathrm{o} 3} \\
\text { bar }\end{array}$ & $\begin{array}{l}\mathrm{p}_{02} \\
\text { bar }\end{array}$ & $\begin{array}{c}\mathrm{T}_{\mathrm{o} 2}=\mathrm{T}_{\mathrm{o} 3} \\
\mathrm{~K}\end{array}$ & $\begin{array}{c}\mathrm{h}_{01} \\
\mathrm{~kJ} / \mathrm{kg}\end{array}$ & $\begin{array}{c}\mathrm{h}_{02}=\mathrm{h}_{03} \\
\mathrm{~kJ} / \mathrm{kg}\end{array}$ \\
\hline 1 & 1.17381 & 1.18936 & 1.25263 & 306.15 & 289.59 & 307.68 \\
\hline 2 & 1.23326 & 1.46679 & 1.50023 & 327.15 & 307.68 & 328.79 \\
\hline 3 & 1.21723 & 1.78542 & 1.82363 & 348.15 & 328.79 & 349.89 \\
\hline 4 & 1.20325 & 2.14831 & 2.19164 & 369.15 & 349.89 & 371.00 \\
\hline 5 & 1.19096 & 2.55855 & 2.60734 & 390.15 & 371.00 & 392.10 \\
\hline 6 & 1.18007 & 3.01926 & 3.07386 & 411.15 & 392.10 & 413.21 \\
\hline 7 & 1.17035 & 3.53358 & 3.59435 & 432.15 & 413.21 & 434.31 \\
\hline 8 & 1.16162 & 4.10470 & 4.17197 & 453.15 & 434.31 & 455.42 \\
\hline 9 & 1.15375 & 4.73579 & 4.80993 & 474.15 & 455.42 & 476.52 \\
\hline 10 & 1.14660 & 5.43007 & 5.51145 & 495.15 & 476.52 & 497.63 \\
\hline 11 & 1.14009 & 6.19078 & 6.27975 & 516.15 & 497.63 & 518.73 \\
\hline 12 & 1.13413 & 7.02117 & 7.11810 & 537.15 & 518.73 & 539.84 \\
\hline
\end{tabular}




\begin{tabular}{ccccccc}
\hline Stage & $\mathrm{p}_{\text {03 }} / \mathrm{p}_{\text {01 }}$ & \multicolumn{1}{c}{$\mathrm{p}_{\text {o3 }}$} & \multicolumn{1}{c}{$\begin{array}{c}\mathrm{p}_{02} \\
\mathrm{bar}\end{array}$} & $\begin{array}{c}\mathrm{T}_{\text {o2 }}=\mathrm{T}_{\text {03 }} \\
\mathrm{K}\end{array}$ & $\begin{array}{c}\mathrm{h}_{01} \\
\mathrm{~kJ} / \mathrm{kg}\end{array}$ & $\begin{array}{c}\mathrm{h}_{02}=\mathrm{h}_{03} \\
\mathrm{~kJ} / \mathrm{kg}\end{array}$ \\
\hline 13 & 1.12866 & 7.92453 & 8.02978 & 558.15 & 539.84 & 560.94 \\
14 & 1.12362 & 8.90415 & 9.01808 & 579.15 & 560.94 & 582.05 \\
15 & 1.11896 & 9.96334 & 10.08633 & 600.15 & 582.05 & 603.15 \\
16 & 1.11463 & 11.10544 & 11.23785 & 621.15 & 603.15 & 624.26 \\
17 & 1.11313 & 12.36165 & 12.50722 & 642.60 & 624.26 & 645.82 \\
\hline
\end{tabular}

Table 9: Variation of air angles from root to tip

\begin{tabular}{|c|c|c|c|c|c|c|c|c|c|c|c|c|}
\hline \multirow{2}{*}{ Stage } & \multicolumn{3}{|c|}{$\alpha_{1}$} & \multicolumn{3}{c|}{$\alpha_{2}$} & \multicolumn{3}{c|}{$\beta_{1}$} & \multicolumn{3}{|c|}{$\beta_{2}$} \\
\cline { 2 - 11 } & Tip & Mean & Root & Tip & Mean & Root & Tip & Mean & Root & Tip & Mean & Root \\
\hline 1 & 11.36 & 15.00 & 21.90 & 29.31 & 36.49 & 47.31 & 60.19 & 50.00 & 29.73 & 53.71 & 35.75 & -5.03 \\
2 & 16.23 & 20.76 & 28.50 & 36.12 & 43.06 & 52.41 & 58.14 & 47.21 & 25.45 & 48.73 & 27.70 & -13.99 \\
3 & 16.64 & 20.63 & 26.94 & 37.03 & 43.14 & 51.04 & 56.99 & 47.28 & 29.80 & 46.63 & 27.58 & -7.44 \\
4 & 16.97 & 20.50 & 25.75 & 37.81 & 43.22 & 49.98 & 56.00 & 47.35 & 32.97 & 44.75 & 27.46 & -2.26 \\
5 & 17.23 & 20.36 & 24.80 & 38.49 & 43.30 & 49.16 & 55.17 & 47.42 & 35.37 & 43.08 & 27.34 & 1.84 \\
6 & 17.42 & 20.22 & 24.03 & 39.08 & 43.39 & 48.51 & 54.45 & 47.50 & 37.24 & 41.57 & 27.22 & 5.11 \\
7 & 17.56 & 20.06 & 23.36 & 39.60 & 43.48 & 48.00 & 53.84 & 47.58 & 38.74 & 40.21 & 27.08 & 7.72 \\
8 & 17.68 & 19.94 & 22.82 & 40.06 & 43.56 & 47.57 & 53.31 & 47.64 & 39.94 & 39.01 & 26.96 & 9.88 \\
9 & 17.75 & 19.79 & 22.33 & 40.47 & 43.64 & 47.24 & 52.86 & 47.72 & 40.95 & 37.91 & 26.83 & 11.64 \\
10 & 17.79 & 19.64 & 21.89 & 40.84 & 43.73 & 46.97 & 52.48 & 47.80 & 41.80 & 36.91 & 26.69 & 13.08 \\
11 & 17.80 & 19.48 & 21.50 & 41.18 & 43.82 & 46.75 & 52.15 & 47.87 & 42.53 & 36.00 & 26.55 & 14.29 \\
12 & 17.79 & 19.33 & 21.13 & 41.49 & 43.92 & 46.58 & 51.87 & 47.95 & 43.16 & 35.16 & 26.41 & 15.30 \\
13 & 17.76 & 19.16 & 20.79 & 41.78 & 44.01 & 46.44 & 51.62 & 48.04 & 43.72 & 34.40 & 26.27 & 16.14 \\
14 & 17.72 & 19.00 & 20.47 & 42.05 & 44.11 & 46.33 & 51.42 & 48.12 & 44.21 & 33.69 & 26.12 & 16.85 \\
15 & 17.65 & 18.83 & 20.17 & 42.30 & 44.20 & 46.25 & 51.25 & 48.20 & 44.64 & 33.03 & 25.96 & 17.45 \\
16 & 17.57 & 18.66 & 19.88 & 42.58 & 44.30 & 46.13 & 51.10 & 48.29 & 45.04 & 32.25 & 25.81 & 18.20 \\
17 & 17.02 & 17.99 & 19.09 & 43.08 & 44.68 & 46.37 & 51.18 & 48.61 & 45.68 & 31.32 & 25.21 & 18.08 \\
\hline
\end{tabular}

Table 10: de Haller number, static pressure rise coefficient and diffusion factor

\begin{tabular}{cccccc}
\hline Stages & $\mathrm{dH}_{\text {rotor }}$ & $\mathrm{dH}_{\text {stator }}$ & $\kappa_{\text {rotor }}$ & $\kappa_{\text {stator }}$ & $\mathrm{DF}$ \\
\hline 1 & 0.792 & 0.860 & 0.373 & 0.261 & 0.473 \\
2 & 0.767 & 0.781 & 0.411 & 0.391 & 0.497 \\
3 & 0.765 & 0.779 & 0.414 & 0.393 & 0.496 \\
4 & 0.764 & 0.777 & 0.417 & 0.396 & 0.495 \\
5 & 0.762 & 0.776 & 0.420 & 0.399 & 0.494 \\
6 & 0.760 & 0.774 & 0.423 & 0.401 & 0.493 \\
7 & 0.758 & 0.772 & 0.426 & 0.404 & 0.492 \\
8 & 0.756 & 0.770 & 0.429 & 0.407 & 0.491 \\
9 & 0.754 & 0.768 & 0.432 & 0.410 & 0.490 \\
10 & 0.752 & 0.766 & 0.435 & 0.413 & 0.488 \\
11 & 0.750 & 0.765 & 0.438 & 0.415 & 0.487 \\
12 & 0.748 & 0.763 & 0.441 & 0.418 & 0.485 \\
13 & 0.746 & 0.761 & 0.444 & 0.421 & 0.483 \\
14 & 0.744 & 0.759 & 0.447 & 0.424 & 0.481 \\
15 & 0.741 & 0.757 & 0.450 & 0.428 & 0.479 \\
16 & 0.739 & 0.752 & 0.454 & 0.434 & 0.477 \\
17 & 0.731 & 0.748 & 0.466 & 0.441 & 0.469 \\
\hline
\end{tabular}




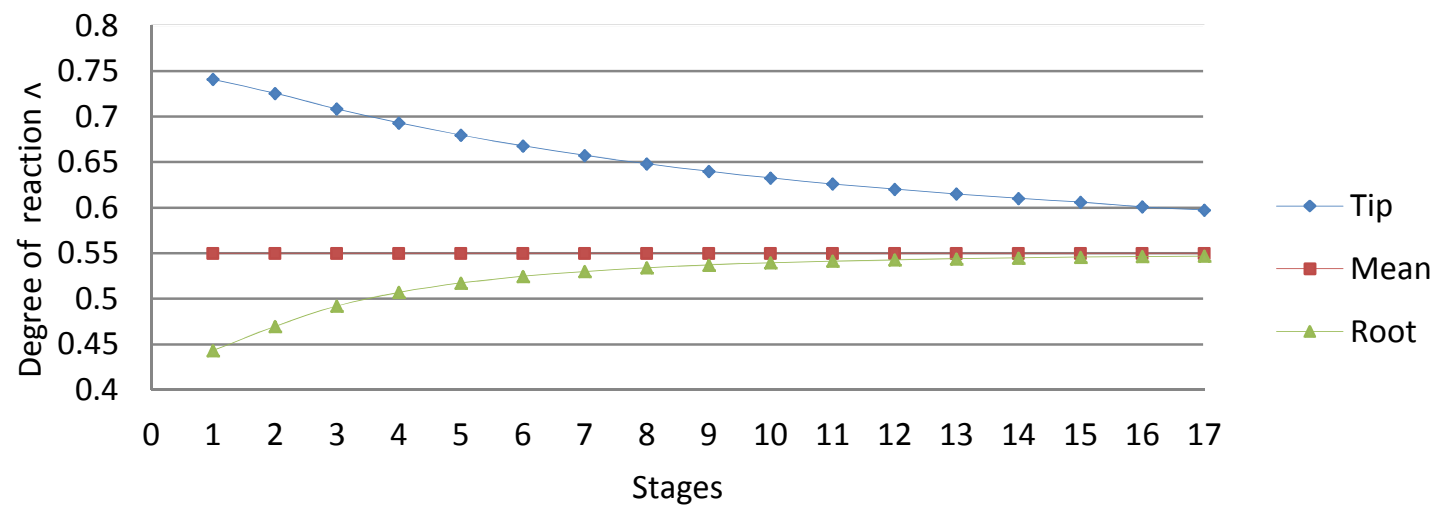

Figure 6: Variation of degrees of reaction ratios

Table 11: Blade geometry

\begin{tabular}{ccccccccccccccc}
\hline Stage & $\mathrm{N}_{\text {rotor }}$ & $\begin{array}{c}\mathrm{S}_{\text {rotor }} \\
\mathrm{m}\end{array}$ & $\begin{array}{c}\mathrm{c}_{\text {rotor }} \\
\mathrm{m}\end{array}$ & $\mathrm{AR}_{\text {rotor }}$ & $\begin{array}{c}\mathrm{N}_{\text {stator }} \\
\text { c }\end{array}$ & $\begin{array}{c}\mathrm{S}_{\text {stator }} \\
\mathrm{m}\end{array}$ & $\begin{array}{c}\mathrm{c}_{\text {stator }} \mathrm{m} \\
\mathrm{m}\end{array}$ & $\mathrm{AR}_{\text {stator }}$ & $\mathrm{i}_{\text {ref }}$ & $\delta_{\text {(i=iref) }}$ & $\beta_{b 1}$ & $\beta_{b 2}$ & $\Theta$ \\
\hline 1 & 13 & 0.214 & 0.122 & 2.413 & 14 & 0.198 & 0.072 & 3.708 & -7.21 & 16.23 & 57.20 & 19.52 & 37.68 \\
2 & 17 & 0.163 & 0.117 & 2.287 & 26 & 0.107 & 0.067 & 3.409 & -5.91 & 12.76 & 53.12 & 14.94 & 38.18 \\
3 & 19 & 0.146 & 0.106 & 2.157 & 28 & 0.099 & 0.063 & 3.138 & -5.78 & 12.47 & 53.06 & 15.12 & 37.94 \\
4 & 23 & 0.121 & 0.089 & 2.224 & 32 & 0.087 & 0.056 & 3.091 & -5.64 & 12.18 & 52.99 & 15.29 & 37.70 \\
5 & 27 & 0.103 & 0.077 & 2.242 & 34 & 0.082 & 0.054 & 2.851 & -5.49 & 11.89 & 52.92 & 15.45 & 37.46 \\
6 & 29 & 0.096 & 0.074 & 2.082 & 38 & 0.073 & 0.049 & 2.783 & -5.34 & 11.60 & 52.84 & 15.62 & 37.22 \\
7 & 31 & 0.090 & 0.071 & 1.933 & 40 & 0.069 & 0.047 & 2.573 & -5.17 & 11.28 & 52.75 & 15.80 & 36.95 \\
8 & 37 & 0.075 & 0.060 & 2.023 & 42 & 0.066 & 0.046 & 2.389 & -5.03 & 11.02 & 52.67 & 15.94 & 36.73 \\
9 & 37 & 0.075 & 0.062 & 1.779 & 44 & 0.063 & 0.045 & 2.221 & -4.86 & 10.73 & 52.58 & 16.10 & 36.48 \\
10 & 31 & 0.068 & 0.057 & 1.741 & 46 & 0.060 & 0.043 & 2.069 & -4.69 & 10.44 & 52.48 & 16.25 & 36.23 \\
11 & 41 & 0.068 & 0.058 & 1.543 & 48 & 0.058 & 0.042 & 1.930 & -4.50 & 10.15 & 52.38 & 16.41 & 35.97 \\
13 & 43 & 0.065 & 0.057 & 1.439 & 50 & 0.056 & 0.042 & 1.803 & -4.31 & 9.86 & 52.27 & 16.55 & 35.71 \\
14 & 47 & 0.059 & 0.053 & 1.403 & 50 & 0.056 & 0.042 & 1.622 & -4.11 & 9.57 & 52.15 & 16.70 & 35.45 \\
15 & 49 & 0.059 & 0.055 & 1.255 & 50 & 0.056 & 0.043 & 1.463 & -3.90 & 9.27 & 52.02 & 16.84 & 35.17 \\
16 & 51 & 0.054 & 0.053 & 1.096 & 52 & 0.053 & 0.045 & 1.146 & -3.44 & 8.69 & 51.72 & 17.12 & 34.60 \\
17 & 57 & 0.049 & 0.054 & 1.011 & 52 & 0.053 & 0.047 & 1.007 & -2.43 & 7.63 & 51.05 & 17.58 & 33.46 \\
\hline
\end{tabular}

Table 12: Validation of Results

\begin{tabular}{|c|c|c|c|c|}
\hline & & \multicolumn{2}{|c|}{ Calculated } & \multirow{2}{*}{$\begin{array}{c}\text { GTII } 27^{\circ} \mathrm{C} \\
\text { ambient }\end{array}$} \\
\hline & & $\begin{array}{c}15^{\circ} \mathrm{C} \\
\text { ambient }\end{array}$ & $\begin{array}{c}27^{\circ} \mathrm{C} \\
\text { ambient }\end{array}$ & \\
\hline $\begin{array}{l}\text { Overall st } \\
\text { temperature }\end{array}$ & $\begin{array}{l}\text { stagnation } \\
\text { ure rise, } \Delta \mathrm{T}_{0}\end{array}$ & $354.46^{\circ} \mathrm{C}$ & $368.98^{\circ} \mathrm{C}$ & $375.88^{\circ} \mathrm{C}$ \\
\hline $\begin{array}{l}\text { Compressor } \\
\text { done, WD }\end{array}$ & work & $51.5 \mathrm{MW}$ & $53.6 \mathrm{MW}$ & $54.6 \mathrm{MW}$ \\
\hline $\begin{array}{l}\text { Total to } \\
\text { efficiency, } \eta_{\mathrm{tt}}\end{array}$ & Total & 0.86 & 0.86 & \\
\hline
\end{tabular}

\subsection{Discussion}

Table 7 indicates the values of the static properties as the flow progresses from stage 1 to stage 17 of the axial flow compressor. The values of the static pressure (p), enthalpy (h) and density ( $\rho$ ) of the air increase gradually across the compressor stages. These rises in static pressure and enthalpy are the result of the transfer and transformation of kinetic energy. The static property rises are as expected in the behavior of a compressor cascade as the rotor and stator blades are designed to diffuse the working fluid (air).

Table 8 indicates the stagnation properties of the air across the entire compressor stages. The stagnation pressures in the rotor $\left(\mathrm{p}_{02}\right)$ and stator $\left(\mathrm{p}_{03}\right)$ blades as well as the stagnation temperature $\left(\mathrm{T}_{02}\right.$ or $\left.\mathrm{T}_{03}\right)$ increase across the length of the compressor cascade. This indicates that there is work done by the compressor on the working fluid.

Table 9 indicates the values of the air angles $\alpha_{1}, \alpha_{2}, \beta_{1}$ and $\beta_{2}$ at the tip, mean and root of the rotor radii for the entire stages 1 to 17 of axial flow compressor.

Table 10 shows the values of de Haller number, static pressure rise coefficient $(\kappa)$ and rotor diffusion factor for flow through the compressor. The de Haller 
number in the rotor or stator varies from 0.731 to 0.86 . These values are greater than 0.72 which is the recommended minimum value for a good design with minimum likelihood for boundary layer growth and wall stall $[16,17]$. An examination of Figure 10 shows a sharp increase in the value of $\kappa$ occurs in both the stator and rotor between stages 1 and 2. This sharp increase will result in higher losses and surge in these stages. However, the losses in all other stages in the Korch surge curve are conservative and this agrees closely with the work of [2]. The diffusion factors for the rotor in the various stages are lower than 0.6. Designs of axial flow compressors are usually limited to diffusion factors less than or equal to 0.6 [18]).

Figure 6 shows the degree of reaction $(\wedge)$ at the root, mean and tip of the rotor radii for entire length of the compressor cascade. The degree of reaction at the root and tip converges towards the $\wedge_{\mathrm{m}}$ value of 0.55 at the mean radius as it moves from stage 1 to 17 . While the tip degree of reaction reduces across the stages, the root degree of reaction increases. The convergence towards 0.55 of the tip and root degrees of reaction indicates a more uniform load distribution across the compressor cascade.

Table 11 shows various parameters obtained from the blade design calculations. The number of blades $(\mathrm{N})$, pitch (s), chord length (c), aspect ratio (AR) for both rotor and stator are indicated for all stages of the axial flow compressor. The blade camber angle $(\theta)$ for each stage is also shown.

Table 12 presents some performance data of the axial flow compressor installed in Omotosho Phase I Gas Turbine Unit II as well as results obtained from the computer program that was written based on the formulated algorithm. The values obtained at $27{ }^{\circ} \mathrm{C}$ ambient temperature agrees reasonably well with that obtained from the plant manufacturers. Therefore the algorithm is valid and can be applied to design compressors for similar weather conditions as in Omotosho.

\section{CONCLUSION}

The paper has presented the development of an algorithm that can be used for the preliminary design of an axial flow compressor of a power generation gas turbine. Various parameters have been considered in the algorithm and the designed compressor is conservative in terms of losses as the de Haller number obtained for both rotor and stator blades along the seventeen stages are greater than the minimum recommended value of 0.72 . The diffusion factor which is a measure of the amount of diffusion was less than 0.6. The power input to the compressor at $27^{\circ} \mathrm{C}$ ambient air temperature for the preliminary design is $53.6 \mathrm{MW}$ which is in good agreement with the value of 54.6MW for the compressor of Unit GT-II in Omotosho Phase I Thermal Power Station. This validates the design procedure and parameters obtained. Data such as stage by stage performance and blade design parameters that were computed in this work are not published in the open literature by manufacturers of gas turbine axial flow compressors. Finally, it must be stated that the successful design of an axial flow compressor is an art, and all major manufacturers of gas turbine compressors have developed a body of knowledge which is kept proprietary for commercial reasons.

\section{ACKNOWLEDGEMENT}

The authors wish to express their profound gratitude to the management and staff of Omotosho Phase I Thermal Power Plant for allowing the use of their facility and providing some of the data to conduct this study.

\section{NOMENCLATURE}

\begin{tabular}{ll}
\hline Symbol & Description \\
\hline $\mathrm{A}$ & Area $\left[\mathrm{m}^{2}\right]$ \\
$\mathrm{a}$ & Sonic velocity $[\mathrm{m} / \mathrm{s}]$ \\
$\mathrm{AR}$ & Aspect ratio \\
$\mathrm{C}$ & Absolute velocity $[\mathrm{m} / \mathrm{s}]$ \\
$\mathrm{C}$ & Chord length $[\mathrm{m}]$ \\
$\mathrm{C}_{\mathrm{p}}$ & Specific heat capacity at constant pressure $[\mathrm{kJ} / \mathrm{kgK}]$ \\
$\mathrm{DF}$ & Diffusion factor \\
$\mathrm{dH}$ & de Haller number \\
$\mathrm{H}$ & Blade height $[\mathrm{m}]$ \\
$\mathrm{h}$ & Static enthalpy $[\mathrm{kJ} / \mathrm{kg}]$ \\
$\mathrm{h}_{\mathrm{o}}$ & Stagnation enthalpy $[\mathrm{kJ} / \mathrm{kg}]$ \\
$\mathrm{I}$ & Incidence angle $[\mathrm{o}]$ \\
$\mathrm{M}$ & Mach number \\
$\dot{\mathrm{m}}$ & Mass flow rate $[\mathrm{kg} / \mathrm{s}]$ \\
$\mathrm{N}_{\mathrm{b}}$ & Number of blades \\
$\mathrm{N}_{\mathrm{s}}$ & Number of stages \\
$\mathrm{n}$ & Index of compression \\
$\mathrm{p}$ & Static pressure $[\mathrm{bar}]$ \\
$\mathrm{p}_{\mathrm{o}}$ & Stagnation pressure $[\mathrm{bar}]$ \\
$\mathrm{R}$ & Specific gas constant $[\mathrm{J} / \mathrm{kgK}]$ \\
$\mathrm{RPM}$ & Rotational speed $[\mathrm{rev} / \mathrm{min}]$ \\
$\mathrm{r}$ & Radius [m] \\
$\mathrm{r}_{\mathrm{p}}$ & Pressure ratio \\
$\mathrm{S}$ & Staggered spacing $[\mathrm{m}]$ \\
$\mathrm{s}$ & Specific entropy $[\mathrm{kJ} / \mathrm{kgK}]$ \\
$\mathrm{T}$ & Static temperature $[\mathrm{K}]$ \\
$\mathrm{T}$ o & Stagnation temperature $[\mathrm{K}]$ \\
$\mathrm{t}$ & Maximum blade thickness $[\mathrm{m}]$ \\
$\mathrm{U}$ & Blade speed $[\mathrm{m} / \mathrm{s}]$ \\
\hline & Relative velocity $[\mathrm{m} / \mathrm{s}]$ \\
\hline &
\end{tabular}

\section{Greek Symbols}




\begin{tabular}{ll}
\hline Symbol & Description \\
\hline A & $\begin{array}{l}\text { Angle between absolute velocity and axial direction } \\
\end{array}$ \\
B & Ao] \\
& Angle between relative velocity and axial direction \\
$\Gamma$ & {$\left[{ }^{\circ}\right]$} \\
$\Delta$ & Specific heat capacity ratio \\
$\Delta$ & Change \\
$\mathrm{E}$ & Deviation angle $\left[{ }^{\circ}\right]$ \\
$\eta_{\mathrm{p}}$ & End wall clearance $[\mathrm{m}]$ \\
$\Theta$ & Polytropic efficiency \\
$\mathrm{K}$ & Blade camber angle $\left[{ }^{\circ}\right]$ \\
$\Lambda$ & Pressure rise coefficient \\
$\mathrm{P}$ & Degree of reaction \\
$\Sigma$ & Density $\left[\mathrm{kg} / \mathrm{m}^{3}\right]$ \\
$\Phi$ & Solidity \\
\hline
\end{tabular}

\section{Subscripts}

\begin{tabular}{ll}
\hline O & Stagnation property \\
1 & Rotor inlet property \\
2 & Rotor outlet or Stator inlet property \\
3 & Stator outlet property \\
A & Axial component \\
B & Blade \\
exit & Axial compressor outlet parameter \\
M & Mean \\
R & Root \\
ref & Reference \\
rms & Root mean square \\
S & Stage \\
T & Tip \\
$\Theta$ & Tangential component \\
\hline
\end{tabular}

\section{REFERENCES}

[1].Egware, H.O and Obanor, A.I. "Energy Cost Analysis of Incorporating Air Intake Cooling System in Omotosho Phase I Power Plant", Journal of Energy Technologies and Policy, Vol. 3, No. 7, 2013, pp. 29-33.

[2].Falck, N. "Axial Flow Compressor Mean Line Design", Master Thesis, Division of Thermal Power Engineering, Department of Energy Science, Lund University, Sweden.2008

[3].Unuareokpa, 0.J. "Preliminary Design of an Axial Flow Compressor for Power Generation", M.Eng Thesis, Department of Mechanical Engineering, University of Benin, Benin City, Nigeria 2014.

[4].Dixon, S.L. Fluid Mechanics and Thermodynamics of Turbomachinery, Fifth Edition, Elsevier Butterworth Heinemann, UK, 2005

[5].Saravanamuttoo, H.I.H, Rogers, G.F.C, Cohen, H. and Straznicky, P.V. Gas Turbine Theory, Sixth Edition. Prentice Hall, England, 2009
[6].Adam, 0. A Quasi-One Dimensional Model for Axial Compressor, Turbomachine et Propulsion, Universite de Liege, 4000 Liege, Belgique, 2002

[7].Rizwon, R.R. Preliminary Design Code for Axial Compressor, Naval Postgraduate School, Monterey, Califonia, United States of America, 1994

[8]. Wet L. "Performance of an Axial Flow Helium Compressor under High Through-Flow Condition", Stellenbosch University, Stellenbosch, South Africa, 2010

[9]Behrooz, F, Reza, T and Saeed M. "Preliminary Design Optimization of Axial Compressors", Iranian Journal of Mechanical Engineering, Vol. 5, No. 1, 2004, pp. 6 15.

[10].Howell, A.R. "Fluid Dynamics of Axial Compressors, and Design of Axial Compressors", Proceedings of the Institution of Mechanical Engineers, 153, W.E.P. No. 12.1945

[11].Sang-Yun, L and Kwang-Yong, K. "Design Optimization of Axial Flow Compressor Blades with Three-Dimensional Navier-Stokes Solver", KSME International Journal, Vol. 14, No. 9,200, pp. 10051012.

[12].Ujjawal, A.J., Joshi, S.I. "Design and Analysis of Stator, Rotor and Blades of the Axial flow Compressor", International Journal of Engineering Development and Research, IJEDR1301005, 2013 pp. 24-29

[13]. Tounier J.M and EI-Genk M.S. "Axial flow, MultiStage Turbine and Compressor Models", Energy Conversion and Management 15, 2010 pp 16 -29.

[14].McKenzie, A.B. Axial Flow Fans and Compressors, Ashgate Publishing Limited, Wey Court East, Farnham, GU9 7PT, United Kingdom, 1997

[15].Denton, J D. “Cambridge Turbomachinery Course”, Whittle Laboratory, Department of Engineering, University of Cambridge,2004

[16].Subbarao, P.M.V. "Design of Axial Flow Compressors", Golden Jubilee Lecture, Indian Institute of Technology, Delhi, India, 2011

[17].Ronald, C.P. “Cascade Blade Loading Analysis with Application to Turbomachinery Design", ASME International Mechanical Engineering Congress and Exposition, November 11-15, Seattle, Washington, USA, IMECE 2007-41398, 2007

[18]Mattingly J.D. Element of Gas Turbine Propulsion, Second Reprint, Tata McGraw-Hill, New Delhi, 2009 